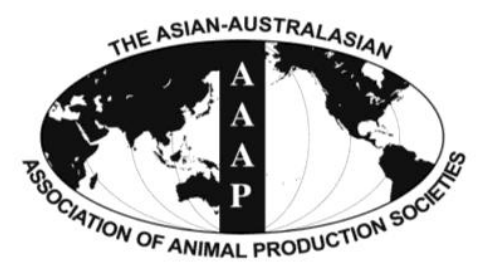

Asian-Aust. J. Anim. Sci.

Vol. 26, No. 2 : 282-286 February 2013

http://dx.doi.org/10.5713/ajas.2012.12419

www.ajas.info

pISSN 1011-2367 elSSN 1976-5517

\title{
Effects of Electrical Stimulation on Lipid Oxidation and Warmed-over Flavor of Precooked Roast Beef
}

\author{
Jen-Hua Cheng* and Herbert W. Ockerman ${ }^{1}$ \\ Department of Nutrition and Health Sciences, Kainan University, Taoyuan County 338, Taiwan
}

\begin{abstract}
Many manufacturing processes damage the structure of meat products and this often contributes to lipid oxidation which could influence warmed-over flavor (WOF) in precooked beef that is reheated beef. Electrical stimulation causes contraction of muscles and improves tissue tenderization. The purpose of this study was to evaluate the rate of lipid oxidation or warmed-over flavor that could be affected by electrical stimulation of precooked roast beef after refrigerated storage and reheating. The results show that there was no significant difference between chemical compositions and cooking yields when comparing non-electrically stimulated and electrically stimulated roast beef. Moreover, electrical stimulation had no significant effect on oxidative stability and off-flavor problems of precooked roast beef as evaluated by thiobarbituric acid reactive substances (TBARS) and sensory test (warmed-over aroma and warmed-over flavor). However, there was an increased undesirable WOF and a decrease in tenderness for both ES and Non-ES treatments over refrigerated storage time. Electrical stimulation did cause reactions of amino acids or other compounds to decrease the desirable beef flavor in re-cooked meat. (Key Words: Electrical Stimulation, Lipid Oxidation, Warmed-over Flavor, Precooked Roast Beef)
\end{abstract}

\section{INTRODUCTION}

Tims and Watts (1958) were the first researchers to describe warmed-over flavor (WOF) as the undesirable flavor of cooked meat during short-term refrigerated storage. Recently, many researchers have indicated many reactions, including lipid oxidation, which is involved in the development of undesirable flavor in meat (Spanier et al., 1988; St. Angelo et al., 1988). Meat flavor deterioration (MFD) is currently used to describe this undesirable flavor (Spanier et al., 1988). However, autoxidation, which is a continuous free radical chain reaction (Pearson et al., 1983), is still hypothesized as the major reaction responsible for WOF of precooked roast beef. WOF makes it difficult to introduce precooked beef products as convenience foods into the market place.

Many processes damage the structure of meat products that could contribute to lipid oxidation and WOF in precooked beef. Electrical stimulation (ES) causes

\footnotetext{
* Corresponding Author: Jen-Hua Cheng. Tel: +886-2-22193813, Fax: +886-3-2705904, E-mail: jhcheng115@yahoo.com.tw

${ }^{1}$ Department of Animal Sciences, The Ohio State University, Columbus, OH 43210, USA.

Submitted Aug. 6, 2012; Accepted Oct. 8, 2012; Revised Oct. 17, 2012
}

contraction of muscle and improves the tenderization process. Dutson et al. (1980) summarized the possible mechanisms of ES to improve meat tenderness, accelerate postmortem glycolysis and rigor mortis, and reduce $\mathrm{pH}$ conditions while the carcass is still hot. Also, micrographs showed that ES clearly disrupted the $\mathrm{Z}$ line. The major goals of ES are to accelerate aging of meat, increase glycolytic activity, and accelerate release of lysosomal enzymes. Disruption of muscle structures could promote lipid oxidation and increase the off-flavor problem in meat. After electrical stimulation, there was no significant difference in shear force values and microbial growth between cooked pre-rigor and cooked post-rigor roast beef (West et al., 1980). From a microbiological standpoint, ES could reduce microbial growth due to lower $\mathrm{pH}$ value of muscle, from elimination of ATP and glycogen, release of proteolytic enzymes, and destroying bacterial cells (Dutson et al., 1980; Mrigadat et al., 1980).

The objectives of this study were to evaluate the rate of lipid oxidation or warmed-over flavor that could be affected by electrical stimulation of precooked roast beef after refrigerated storage and reheating, and to seek the optimum quality of precooked roast beef from the lipid oxidation and warmed-over flavor standpoint. 


\section{MATERIALS AND METHODS}

\section{Sample preparation}

The Ohio State University Meat Laboratory supplied the stimulated meat. A low voltage (40 volts) was used to stimulate one half of the carcass and other half was nonelectrically stimulated. The electrodes of the stimulator were placed in the carcass round and in the atlas on the neck. Stimulation was done 45 times, each by $2.5 \mathrm{~s}$ on and $1.5 \mathrm{~s}$ off. The primal cuts were vacuum packaged for $10 \mathrm{~d}$. Then, the beef round primal cuts were trimmed of visible fat and connective tissue. All beef bottom rounds were cut into uniform cubes of roasts $(8 \times 8 \times 8 \mathrm{~cm}$ dimensions $)$. The muscles were roasted in a hot-air convection oven (Type EFIII, The GS Blodgett Co Inc., Burlington, Vermont) at $168^{\circ} \mathrm{C}$ until the internal temperature (IT) of the roasts reached $71^{\circ} \mathrm{C}$. After roasting, the meat products were chilled in a cooler (Model $7030 \mathrm{~S} / \mathrm{N}$ 75368, Forma Scientific, Division of Mallinckrodt, Inc., Ohio, USA) until the internal temperature of the products reached $4^{\circ} \mathrm{C}$. These meat products were separately placed into unsealed plastic bags for refrigerated storage $\left(4^{\circ} \mathrm{C}\right)$ until being tested. Samples were reheated in a microwave (Model M312, 2450 $\mathrm{Hz}$, Hobart Corp., Troy, Ohio, USA) to an IT of $60^{\circ} \mathrm{C}$ before conducting all evaluations, except for the microbiological test that was performed on non-reheated tissue.

Moisture content, $\mathrm{pH}$ values and crude fat contents were evaluated for compositions of raw material (Ockerman, 1985). A modified extraction of the TBARS method was used to analyze lipid oxidation (Pensel, 1990). The results of electrical stimulation were evaluated by yields, WarnerBratzler shear value (Ockerman, 1985), and sensory test (Figure 1).

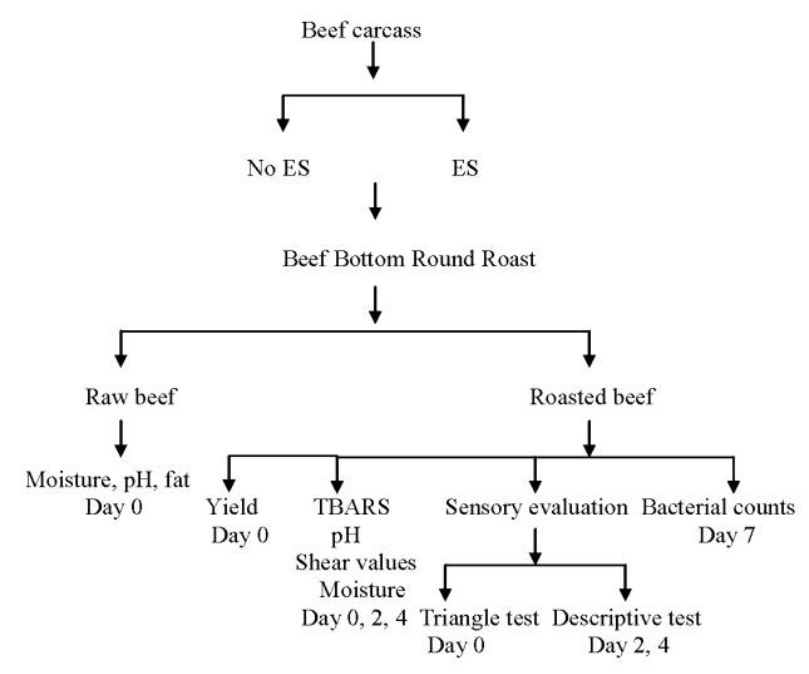

Figure 1. Experimental procedure.

\section{TBARS values determination}

A 5-gram sample was analyzed by the modified extraction method of TBARS. The 5-gram sample of meat tissue was placed in a polyethylene bag. Fifty $\mathrm{ml}$ of chilled $\left(4^{\circ} \mathrm{C}\right)$ solution of $20 \%$ trichloroacetic acid in $1.6 \%$ phosphoric acid was added to the same bag and massaged for two minutes in a stomacher to mix the sample. Fifty $\mathrm{ml}$ of chilled distilled water $\left(4^{\circ} \mathrm{C}\right)$ was then added into the bag and the stomacher was again used to blend the sample for $30 \mathrm{~s}$. The slurry was filtered through Whatman No. 1 filter paper into a $100 \mathrm{ml}$ cylinder. Five $\mathrm{ml}$ of the filtrate was pipetted into a test tube, and five $\mathrm{ml}$ of fresh chilled $0.02 \mathrm{M}$ 2-thiobarbituric acid solution was added to this tube. All samples in test tubes were placed in the dark at room temperature $\left(25^{\circ} \mathrm{C}\right)$ for $15 \mathrm{~h}$ in order to develop the color reaction. The intensity of color was measured in a spectrophotometer at $532 \mathrm{~nm}$ to calculate the TBARS value.

\section{Standard curves of TBARS test}

Two point two grams of 1,1,3,3-tetraethoxypropane (TEP, FW = 220) was diluted to $1000 \mathrm{ml}$ with distilled water to prepare for a $10^{-2} \mathrm{M}$ stock solution. A $10^{-3} \mathrm{M}$ stock solution of TEP was prepared by diluting one milliliter of the $10^{-2} \mathrm{M}$ TEP solution with nine milliliter of distilled water. Zero, 0.1, 0.2, 0.3, 0.4, 0.5, 0.6, 0.7, 0.8, and $0.9 \mathrm{ml}$ volumes of the $10^{-3} \mathrm{M}\left(10^{-6}\right.$ moles of TEP) stock solution was pipetted into a $50 \mathrm{ml}$ volumetric flask, and then diluted to volume with distilled water. Five milliliters of each diluted solution was mixed with $5 \mathrm{ml}$ of $0.02 \mathrm{M}$ thiobarbituric acid solution in each of the test tubes. These test tubes were placed in the dark to develop color for $15 \mathrm{~h}$. The absorbance of the samples is measured by spectrophotometer at $532 \mathrm{~nm}$.

\section{Cooking yield}

Cooking yield

$=($ final product weight $/$ fresh meat weight $) \times 100$

\section{Sensory evaluation}

A triangle test and a descriptive analysis by a trained panel were used in this study. The formal testing followed the modified procedures of Love (1988), St. Angelo et al. (1988), and Meilgaard et al. (1991). For evaluating oxidative flavor of beef and basic beef taste, panelists were screened with an odor of an acid solution and saltiness in a precooked roast beef by the triangle test. A six-member panel consisting of a faculty member, graduate students, and a visiting scholar from Department of Animal Sciences, The Ohio State University were utilized. Before formal testing, two training sessions of $1 \mathrm{~h}$ each were conducted to educate panelists on standard references and to develop the standardized attributes of precooked roast beef and intensity 
of attributes. The standard reference of roast beef flavor was fresh roasted beef that was refrigerated for less than $4 \mathrm{~h}$. The standard reference of WOA (warmed-over aroma was observed by smelling) and WOF (warmed-over flavor was observed by tasting) was precooked roast beef after 4-d of refrigerated storage. The tenderness scores were standardized by agreement among panelists after comparing fresh cooked beef with a variety of tenderness. All standard references were reheated by a microwave at each test day. A 9-point category scale (Table 1) was utilized to discriminate the quantitative properties of precooked roast beef. A triangle test was used to evaluate difference of treatments at $\mathrm{d} 0$, and the descriptive analysis was conducted at $\mathrm{d} 2$ and 4 . When the reheated samples reached an internal temperature of $60^{\circ} \mathrm{C}$, they were presented to the panelist under standard evaluation condition (Meilgaard et al., 1991). The treatments were coded with 3-digit random numbers, placed on a warm plate, covered with aluminum foil and served to the panelists. Panelists evaluated samples in private booths under red light to eliminate color bias. Water and unsalted crackers were served to panelists and standard references (fresh roast beef, reheated roast beef and beef of different tenderness) were provided to panelists each evaluation day.

\section{Microbiological tests}

Total aerobic, psychrotrophic, and thermophilic bacteria tests were used to detect contamination of various bacteria in precooked roast beef which was not reheated after refrigerated storage on the day of test. Total aerobic plate count was evaluated using aerobic plate count agar (APC agar; Difco Laboratory, Detroit, Michigan, USA) at an incubation temperature of $25^{\circ} \mathrm{C}$ for $4 \mathrm{~d}$ (Speck, 1984). Psychrophilic bacteria were tested using APC agar at $4^{\circ} \mathrm{C}$ for $10 \mathrm{~d}$. To get thermophilic counts, aliquots were plated on APC agar at $35^{\circ} \mathrm{C}$ for $48 \mathrm{~h}$. The number of bacteria was converted to $\log _{10}$ colony forming units per gram $\left(\log _{10} \mathrm{CFU} / \mathrm{g}\right)$.

\section{Statistical analysis}

A general linear model (GLM) was used to analyze the
Table 2. Effect of electrical stimulation on $\mathrm{pH}$ values and roast beef flavor scores of precooked roast beef during refrigerated storage

\begin{tabular}{lclc}
\hline & \multicolumn{3}{c}{ Days } \\
\cline { 2 - 4 } & 0 & 2 & 4 \\
\hline PH values & & & \\
NonES & $5.88^{\mathrm{a}}$ & 5.87 & $5.92^{\mathrm{b}}$ \\
ES $^{1}$ & $5.79^{\mathrm{Cb}}$ & $5.88^{\mathrm{B}}$ & $5.98^{\mathrm{Aa}}$ \\
RBF $^{1}$ & & & \\
NonES $^{1}$ & $\mathrm{NE}^{1}$ & $5.88^{\mathrm{Aa}}$ & $6.06 \mathrm{a}^{\mathrm{Ab}}$ \\
ES $^{1}$ & $\mathrm{NE}^{1}$ & $6.06^{\mathrm{Aa}}$ & $4.83 \mathrm{~b}^{\mathrm{Ba}}$ \\
\hline
\end{tabular}

${ }^{1}$ NonES = Non-electrically stimulated; ES = Electrically stimulated; RBF $=$ Roast beef flavor score evaluated by the trained panel; $\mathrm{NE}=\mathrm{Not}$ evaluated.

A,B,C Means with different uppercase superscripts within the same row of one measurement are significantly different $(\mathrm{p}<0.05)$.

a,b Means with different lowercase superscripts within the same column of one measurement are significantly different $(\mathrm{p}<0.05)$.

data by the Statistical Analysis System (SAS). Multiple comparisons of significant differences were determined by Duncan's multiple range at $\alpha=0.05$.

\section{RESULTS AND DISCUSSION}

There was no significant difference of moisture content and fat content between non-electrically stimulated (nonES) and electrically stimulated (ES) fresh beef bottom rounds. However, ES fresh roast beef had significantly lower $\mathrm{pH}$ values when compared to non-ES samples as would be expected. Stimulation significantly increased the $\mathrm{pH}$ decline of fresh meat which has been reported (Dutson et al., 1980; Ockerman and Szczawinski, 1983). Cooking yields for non-ES and ES roasted beefs were not significantly different. Basically, electrical stimulation did not change the composition of roast beef significantly.

The $\mathrm{pH}$ values of precooked roast beef had a two-way interaction $(p<0.01)$ between stimulation and days; that is, the effect of electrical stimulation on $\mathrm{pH}$ was interacting with storage days. Non-ES post rigor precooked roast beef maintained the same $\mathrm{pH}$ for up to $4 \mathrm{~d}$ of refrigerated storage

Table 1. A 9-point category scores for descriptive attributes of precooked roast beef

\begin{tabular}{llll}
\hline WOA & \multicolumn{1}{c}{ WOF } & \multicolumn{1}{c}{ RBF } & Tenderness \\
\hline 1. Extremely bland & 1. Extremely bland & 1. Extremely bland & 1. Extremely tough \\
2. Very bland & 2. Very bland & 2. Very bland & 2. Very tough \\
3. Moderately bland & 3. Moderately bland & 3. Moderately bland & 3. Moderately tough \\
4. Slightly bland & 4. Slightly bland & 4. Slightly bland & 4. Slightly tough \\
5. Neither bland or intense & 5. Neither bland or intense & 5. Neither bland or intense & 5. Neither tough or tender \\
6. Slightly intense & 6. Slightly intense & 6. Slightly intense & 6. Slightly tender \\
7. Moderately intense & 7. Moderately intense & 7. Moderately intense & 7. Moderately tender \\
8. Very intense & 8. Very intense & 8. Very intense & 8. Very tender \\
9. Extremely intense & 9. Extremely intense & 9. Extremely intense & 9. Extremely tender
\end{tabular}

WOA $=$ Warmed-over aroma; $\mathrm{WOF}=$ Warmed-over flavor; $\mathrm{RBF}=$ Roast beef flavor. 
( $>0.05$ ); however, the lower post mortem $\mathrm{pH}$ of ES roast beef increased $(\mathrm{p}<0.05)$ during 4 days of storage (Table 2$)$. At $\mathrm{d} 0$, cooked ES roast beef had a lower $(\mathrm{p}<0.05) \mathrm{pH}$ than Non-ES as would be expected, but ES had a higher $\mathrm{pH}$ at $\mathrm{d}$ $4(\mathrm{p}<0.05)$.

For lipid oxidation (Table 3), TBARS values of Non-ES and ES were increased $(\mathrm{p}<0.05)$ during $4 \mathrm{~d}$ of refrigerated storage, but there was no effect due to stimulation $(\mathrm{p}>0.05)$. The electrical stimulation could release enzymes or pathways for oxygen penetration to promote lipid oxidation by disrupting muscle structure. However, the cooking process also releases a great amount of catalyses by muscle denaturation and would promote chemical oxidation; therefore, the stability of lipid oxidation is not greatly influenced by stimulation (40 volts) when compared with the high temperature of roasting $\left(71^{\circ} \mathrm{C}\right)$. With stimulation effects there was a significant increase oxidation over time as would be expected.

At d 0 , only three panelists discriminated treatments correctly by the triangle test. Therefore, there was no significant difference between the two treatments because a significance $(\alpha=0.05)$ only occurs when at least five out of a six panel members have the correct answers (Meilgaard et al., 1991). Comparisons (Table 3) of WOA, WOF, and tenderness scores indicated that there was no significant difference for NonES and ES. WOA scores of both treatments did not significantly change, but WOF scores significantly increased and tenderness scores significantly decreased during storage.

Roast Beef Flavor (RBF) was influenced by electrical stimulation and was dependent on storage time (Table 2). From d 2 to $\mathrm{d} 4$ in refrigerated storage at $4{ }^{\circ} \mathrm{C}$, precooked roast beef without ES did not significantly change; however, ES had a significantly decreasing score during the same period (6.06 dropped to 4.83). That is the reason ES had lower $(\mathrm{p}<0.05)$ RBF scores than NonES at d 4 (Table 2). Sekikawa et al. (1999) indicated that ES increased the content of free amino acids due to protein degradation via proteases and other enzymes during this process. One amino acid, such as alanine, was decreased slightly during storage compared with the non-electrically stimulated treatment. There was no significant difference in this research due to the stimulation as measured by TBARS and sensory test (WOF and WOA). But, electrical stimulation did cause a decrease of desirable roast beef flavor probably due to complicated reactions of other materials such as amino acids.

Shear values (Table 3) indicated that stimulation produced a significantly more tender precooked roast beef when compared with Non-ES. However, the trained panel did not detect this difference in tenderness. It could be that the objective method is more sensitive than the subjective tenderness evaluation and also low voltage stimulation was used in the present study that is often not as effective at increasing tenderness as high voltage stimulation. With stimulation effects a significant decrease in shear tenderness was indicated which was agreed by the evaluation panelists.

Total bacterial counts were numerically lower for electrical stimulation tissue, but did not significantly change the mesophile, thermophile, and psychrotrophile growth in precooked roast beef at d 7. Ockerman and Szczawinski (1983) reported a reduction of microflora by ES that became less significantly important in an inoculated beef tissue with storage time.

There was no significant difference between chemical compositions and cooking yields between the control (NonES) and the electrically stimulated (ES) roast beef. TBARS and sensory test (WOA and WOF) shows that electrical stimulation had no significant effect on oxidative stability and off-flavor problems of precooked roast beef. Also, there was an increased undesirable WOF and a decrease in tenderness for both ES and Non-ES treatments over time. The electrical stimulation did cause a significantly less desirable roasting flavor after $4 \mathrm{~d}$ of storage that may be caused by reactions of amino acids or other compounds in cooked meat.

Table 3. Main effect of electrical stimulation or time on TBARS values, shear values, WOA, WOF and tenderness of precooked roast beef

\begin{tabular}{|c|c|c|c|c|c|}
\hline Main effect & $\begin{array}{l}\text { TBARS value } \\
(\mathrm{mg} / \mathrm{kg})\end{array}$ & $\begin{array}{l}\text { Shear value } \\
\left(\mathrm{kg} / \mathrm{cm}^{2}\right)\end{array}$ & $\mathrm{WOA}^{1}$ & $\mathrm{WOF}^{1}$ & Tenderness $^{1}$ \\
\hline \multicolumn{6}{|c|}{ Stimulation (Time effects absorbed) } \\
\hline NonES & $0.50^{\mathrm{A}}$ & $4.39^{\mathrm{A}}$ & $4.09^{\mathrm{A}}$ & $4.54^{\mathrm{A}}$ & $5.89^{\mathrm{A}}$ \\
\hline ES & $0.46^{\mathrm{A}}$ & $3.59^{\mathrm{B}}$ & $3.53^{\mathrm{A}}$ & $4.22^{\mathrm{A}}$ & $6.53^{\mathrm{A}}$ \\
\hline \multicolumn{6}{|c|}{ Time (Stimulation effects absorbed) } \\
\hline 0 & $0.28^{\mathrm{c}}$ & $2.99^{c}$ & $\mathrm{NE}$ & $\mathrm{NE}$ & $\mathrm{NE}$ \\
\hline 2 & $0.45^{\mathrm{b}}$ & $3.99^{\mathrm{b}}$ & $3.71^{\mathrm{a}}$ & $3.94^{\mathrm{b}}$ & $6.63^{\mathrm{a}}$ \\
\hline 4 & $0.71^{\mathrm{a}}$ & $5.00^{\mathrm{a}}$ & $3.89^{\mathrm{a}}$ & $4.81^{\mathrm{a}}$ & $5.81^{\mathrm{b}}$ \\
\hline
\end{tabular}

${ }^{1}$ WOA $=$ Warmed-over aroma score was observed by smelling; WOF = Warmed-over flavor score was observed by tasting; Tenderness $=$ Tenderness score evaluated by the trained panel.

${ }^{\mathrm{A}, \mathrm{B}}$ Means with different uppercase superscripts within main effect of stimulation are significantly different $(\mathrm{p}<0.05)$.

a,b,c Means with different lowercase superscripts within main effect of time are significantly different $(\mathrm{p}<0.05)$. 


\section{REFERENCES}

Dutson, T. R., G. C. Smith, J. W. Savell and Z. L. Carpenter. 1980. Possible mechanisms by which electrical stimulation improves meat tenderness. In: 26th European Meeting of Meat Research Worker, Proceedings 2:84-87.

Love, J. D. 1988. Sensory analysis of warmed-over flavor in meat. Food Technol. 42:140-143.

Meilgaard, M., G. V. Civille and B. T. Carr. 1991. Chapter 3: Control for test room, product, and panel, pp. 23-36; Table 17 of triangle test for difference, p. 338. In: Sensory Evaluation Techniques, 2rd. CRC Press, Inc., FL, USA.

Mrigadat, B., G. C. Smith, T. R. Dutson, L. C. Hall, M. O. Hanna and C. Vaderzant. 1980. Bacteriology of electrically stimulated and unstimulated rabbit, pork, lamb, and beef carcasses. J. Food Prot. 43:686-693.

Ockerman, H. W. 1985. Quality control of Post-Mortem Muscle Tissue. Dept. of Animal Sciences, The Ohio State University, Columbus, OH, USA.

Ockerman, H.W. and J. Szczawinski. 1983. Effect of electrical stimulation on the microflora of meat. J. Food Sci. 48:10041005.
Pearson, A. M., J. I. Gray, A. M. Wolzak and N. A. Horenstein. 1983. Safety implications of oxidized lipids in muscle foods. Food Technol. 37:121-129.

Pensel, N. A. 1990. Influence of experimental conditions on porcine muscle and its effect on oxidation. A thesis, The Ohio State University, Columbus, OH, USA.

Sekikawa, M, K. Seno, K. Shimada, M. Fukushima and M. Mikami. 1999. Transaminase affects accumulation of free amino acids in electrically stimulated beef. J. Food Sci. 64: 384-386.

Spanier, A. M., J. V. Edwards and H. P. Dupuy. 1988. The warmed-over flavor process in beef: a study of meat protein and peptides. Food Technol. 42:110-118.

Speck, M. L. 1984. "Compendium of methods for the microbiological examination of foods" 2 nd edition by American Health Association Inc., Washington, DC, USA.

St. Angelo, A. J., J. R. Vercellotti, H. P. Dupuy and A. M. Spanier. 1988. Assessment of beef flavor quality: a multidisciplinary approach. Food Technol. 42:133-138.

Tims, M. J. and B. M. Watts. 1958. Protection of cooked meats with phosphates. Food Technol. 12:240-243.

West, R. L., D. M. Langston and J. L. Oblinger. 1980. Storage stability and tenderness of top round roasts cooked pre- or post-rigor following electrical stimulation. In: $26^{\text {th }}$ European Meeting of Meat Research Worker, Proceedings 2:57-60. 